\title{
Service Interruption: Managing Commitment to Community Partners During a Crisis
}

\author{
Lecia J. Barker \\ University of Colorado Boulder \\ Lecia.Barker@colorado.edu
}

\author{
Amy Voida \\ University of Colorado Boulder \\ Amy.Voida@colorado.edu
}

\author{
Vaughan Nagy \\ University of Colorado Boulder \\ Vaughan.Nagy@colorado.edu
}

\begin{abstract}
While the 2020-2021 COVID-19 pandemic is the most widespread and longest lasting educational disruption of the modern era, it joins a host of other natural and human-made crises affecting university education, such as Hurricane María in Puerto Rico (2017), the Islamic State's closure of Al-Furat University in Syria (2014), Hurricane Katrina in New Orleans (2005), and many others. For service learning classes, generally defined as students learning as they provide service to a community partner, these large scale disruptions create special challenges even when it is possible to move classes online. The COVID-19 pandemic seriously affected the active involvement of community partners, including non-profit organizations, local schools and hospitals, and local governments. Many community organizations struggled to meet increased demand for their assistance while simultaneously cutting personnel due to budget shortfalls. In this paper, we report results from 34 survey respondents who offered service learning classes in undergraduate computer and information science during spring 2020. Despite the turmoil, only three faculty respondents lost their community partner entirely. In response to disruption, nearly half of faculty removed some of the assignments' requirements, while others made the service project optional or removed it completely. Going online negatively affected students' ability to collaborate with each other and interact with community partners, activities that are considered important for reaching learning outcomes for service learning. Nevertheless, about two-thirds of faculty reported that their students completed their service assignments and described conditions that led to or detracted from their success. Based on the findings, the authors present several implications for development of future computer and information science service learning offerings that are resilient during times of crisis.
\end{abstract}

\section{CCS CONCEPTS}

- Social and professional topics; • Computer science education;

\section{KEYWORDS}

Service learning, COVID-19, disruption, emergency remote instruction, community partners, computer science, information science

This work is licensed under a Creative Commons

Attribution-NonCommercial-NoDerivs International 4.0 License.

ICER 2021, August 16-19, 2021, Virtual Event, USA

(C) 2021 Copyright held by the owner/author(s).

ACM ISBN 978-1-4503-8326-4/21/08.

https://doi.org/10.1145/3446871.3469756

\section{ACM Reference Format:}

Lecia J. Barker, Amy Voida, and Vaughan Nagy. 2021. Service Interruption: Managing Commitment to Community Partners During a Crisis. In Proceedings of the 17th ACM Conference on International Computing Education Research (ICER 2021), August 16-19, 2021, Virtual Event, USA. ACM, New York, NY, USA, 11 pages. https://doi.org/10.1145/3446871.3469756

\section{INTRODUCTION}

Service learning is a type of experiential education in which educators design course-based learning in the context of authentic problems or goals in active collaboration with community partners [55]. Faculty typically intend for students to acquire learning of course content and skills while gaining deeper understanding and awareness of community needs, altruistic concern for others, and increases in professional identity $[18,19]$. ABET, ACM, and IEEE Computer Society all advocate for supplying students with opportunities to acquire these communication skills in the computer and information science curriculum to improve the quality and diversity of the professional computing workforce $[1,29]$. The ACM/IEEE 2013 curriculum guidelines encourage departments to add explicit career development into courses, writing, "as technological advances continue to significantly impact the way we live and work, the critical importance of social issues and professional practice continues to increase" [29]. Service learning is recommended not only for developing professional skills and civic awareness, however, but for retaining college students, a recommendation empirically supported in multiple meta-analyses [18, 24, 66]. Scholars suggest that because service learning takes place in a context of meaningful and authentic interaction among students, instructors, and community, it becomes more personally and socially relevant. Connecting students to personally meaningful and relevant curriculum and experiences is a major predictor of student retention in computing and may contribute to diversity in computing [5, 21, 23, 38, 45, 47]. Many faculty have integrated service learning as an opportunity to accomplish these outcome goals.

For faculty integrating service learning into their courses, a nontrivial commitment of time and energy is required to orchestrate interaction across multiple organizations. Once they find partners, faculty must set expectations for interaction and projects, make sure the partners and students engage each other appropriately, teach students professional communication and project management skills, set up meetings to fit conflicting schedules, address community partner non-response, and address other challenges [56]. For community partners, participating in service learning is also an extra commitment. With this work being outside of their mission, they have limited technology and human resources to devote to supporting students [12, 50,52]. Course design and constant management of student and partner expectations are critical functions of faculty as they strive to reach student outcome goals. 
When meaningful, authentic interaction between students and community partners is a key vehicle for learning and professional growth, a significant disruption to education can wipe out an instructor's plans. With the sudden move to remote teaching in higher education due to the COVID-19 pandemic in spring 2020 alongside the spectacular disruption of the nonprofit community [67], how were faculty able to carry out their commitment to service learning? Below we provide some answers to this question based on a service learning survey fielded in June and July of 2020. First, we briefly summarize research and experience reports from service learning computer and information science educators, followed by a summary of the disruption to the nonprofit sector resulting from the COVID-19 pandemic. After describing our research methodology and respondent profile, we present and discuss results from the survey. Finally, we discuss how faculty might preemptively prepare service oriented courses to counter the effects of disruptions.

\section{SERVICE-LEARNING RESEARCH IN COMPUTER AND INFORMATION SCIENCE}

Hundreds of studies highlight the student benefits of participating in well-designed service learning courses for meeting academic learning objectives, acquiring professional skills, and improving civic engagement (reported in multiple meta-analyses [10, 18, 66]). Students in service learning courses actively co-construct their learning experiences in authentic situations, which is considered a "high impact practice" for retaining students [31]. Rather than passive consumers of instruction, students spend substantial time on learning activities and gain confidence in integrating their knowledge and skills into real-world situations [18]. Deep interaction and involvement in social and academic processes and practices on campus are shown to result in increased sense of belonging, which is predictive of undergraduate student persistence $[2,14,32,35,44,57,62]$.

In computer and information science education, service learning is promoted for accomplishing content and skill learning objectives as well as for diversifying the students in the major, teaching professional skills, meeting accreditation criteria, and aligning with ACM/IEEE guidelines [1, 3, 13, 29, 45, 46, 48]. A large number of experience reports have been published about integrating service learning at all levels, from introductory to upper division undergraduate to graduate level courses [11, 17, 37, 61, 68]; serving different curricular needs, such as computer literacy, hands-on experience, and capstone courses [20,25,54]; and in a range of topic areas, such as computer-human interaction and security [15, 33, 36, 53]. Faculty describe a wide range of project deliverables, including designing websites, developing software, mentoring elementary or secondary programming or robotics students, teaching Internet literacy to senior citizens, and many others [40, 43, 49]. Faculty also reflect on many aspects of their service learning experiences, such as how to reduce the workload [56, 65], software for managing student teams and community partners [61], and goals to diversify the major $[4,48]$.

The design of effective service learning experiences is important for reaching desired student outcomes, providing genuine benefit for communities, and managing educators' time. Despite the availability of "best practices" (e.g., [30,52]), course design is a significant challenge. The projects themselves need to be thoughtfully constructed so that they provide benefit and not harm to nonprofit partners, for whom the many expenses of technology-related projects can outweigh the value provided: the cost of software and hardware; the staff needed to oversee student presence in offices and to discuss needs or assess prototypes [9, 34, 39, 64]; and resources for maintaining technologies after they are implemented $[12,50,52]$. In addition, accurately scoping projects for an academic term is difficult. Projects are not always completed by the end of the academic term, leaving students unsatisfied [27] and community partners with the "non-delivery problem"; as Rosmaita points out, "a failed project is clearly of no use...; it removes the "service' from 'service learning”' ([50] p. 542). In addition to planning well-scoped projects that integrate content and skill acquisition, a critical element of course design is the explicit teaching of professional skills and project management to students to encourage high quality interaction between students and community partners $[13,58]$. Finally, faculty find themselves planning and managing relationships between student groups and community partners. All in all, service learning requires a strong commitment from faculty members during the best of times; faculty ability to juggle these multiple elements is especially challenged when normal operations are interrupted.

\section{COVID-19'S IMPACT ON THE NONPROFIT SECTOR AND HIGHER EDUCATION}

In March, 2020, the COVID-19 pandemic resulted in stay-at-home orders in cities and countries around the world. In-person classes were moved online in thousands of colleges and universities in at least 188 countries [41]. The disruption of higher education has been documented during many natural disasters, terrorist attacks, and other political situations. However, the COVID-19 pandemic was unprecedented in its long-term, worldwide impact across educational levels and economic sectors [28].

A sector that gets little attention in the media is the nonprofit sector, which suffered dramatic and profound disruption from the pandemic. Nonprofit organizations are frequently referred to as "second responders" in times of crisis. As the Johns Hopkins Center for Civil Society emphasized, the fields served by the nonprofit sector "happen to be some of the most critical fields of human service needed during a pandemic" [51]. As demand for their services increased between March 2020 and March 2021, the nonprofit sector lost close to one million jobs in the United States, amounting to $7.4 \%$ of all nonprofit jobs [42]. Regional surveys of the impact of COVID on nonprofit organizations found that a large proportion of them suspended their activities and services. They reduced capacity, particularly due to the impact of stay-at-home orders and social distancing guidelines on the volunteer workforce; had significant shortfalls in revenue, both from declines in donations and from cancelled in-person fundraising events; and had to invest in technologies for their own staff and for their clients to access services that were moved online [22, 26, 67]. For most of the first year of the pandemic, little help was provided from the government. While the March 2021 American Rescue Plan Act offered significant relief funds for nonprofits [6], early relief efforts, such as the U.S.' 
Coronavirus Aid, Relief, and Economic Security (CARES) Act [59] "channeled most of the available assistance to large, for-profit firms" ([51] p. 15). The 2020-2021 period significantly harmed community organizations. We might therefore theorize that some service learning projects would be abandoned by community partners. Thanks to the strong technology infrastructures of most colleges and universities, higher education faculty fared better than their community partners, providing continuity to classes through remote teaching and adapting their teaching approaches to the virtual medium. A large survey-based study conducted in 2020 (N=897 representing 672 U.S. institutions) showed that only about one-third of higher education faculty had experience teaching remotely before the pandemic [28]. During emergency remote instruction, a large majority of faculty $(80 \%)$ taught synchronously, holding lecture sessions via conferencing software, while $65 \%$ reported recording lectures for asynchronous delivery. Yet the transition online required more than adjusting the medium. About two-thirds of faculty changed their assignments or exams, while half eliminated them altogether. Because of institutional mandates in spring 2020 , about half of faculty allowed students to choose pass/fail grades rather than be graded on the basis of quality, affecting students' motivation to participate. Also, about half of faculty lowered their expectations for what students would be able to do. Computer and information science (CIS) faculty may have fared better going online than their non-CIS colleagues, however. A study conducted in March 2020, just after COVID-19 emergency remote instruction began in the United Kingdom included 119 computer science instructors in a sample of 1,148 higher education faculty [14]. Compared to their non-computer science colleagues, computer science instructors reported feeling more prepared and more confident to teach remotely. However, in open-ended comments, several CIS respondents predicted they would have difficulty teaching certain subjects, such as programming, mathematics, and hands-on group projects.

A survey of CIS faculty conducted by the Computing Research Association provides some insight into how faculty managed courses with project requirements [7]. Among 180 respondents requiring collaborative projects, only about one out of seven discontinued the projects entirely. Similarly, about one of 20 capstone courses was discontinued. About two-thirds of faculty believed that emergency remote teaching took much more time than regular teaching. With respect to impact on students, a large-scale spring 2020 study of more than 18,000 students from 14 college campuses found that a third of students had financial stress as well as increases in psychological stress compared to the previous year [60]. Less well understood is the effect on faculty and students in service learning courses, which require interaction of multiple negatively-affected organizations: higher education institutions and non-profits.

Faculty of well designed and implemented service learning courses might be likened to orchestra conductors, directing and aligning the activities of actors with different needs, attitudes, and abilities. In the context of emergency remote teaching, we might expect their ability to orchestrate to be greatly reduced. In the next sections, we address the following research question:

How did the COVID-19 pandemic affect service learning courses in computer and information science? In particular,
- What changes did the COVID-19 pandemic lead to in service learning courses in computer and information science?

- How did these changes affect course outcomes?

- How did faculty, students, and partners overcome the constraints imposed by the COVID-19 pandemic?

\section{METHODS}

The study presented here is the first phase of a multi-method study examining ways to support computer and information science faculty in designing service learning courses that equally serve both students and community partners. In June and July of 2020, we conducted a survey to explore faculty experiences with service learning. One hundred seventy three faculty members responded to the survey; of those respondents, 88 reported that they had taught one or more courses integrating a service learning experience. For the 88 respondents who had taught at least one service learning course, we asked them to answer a series of questions about the most recent service learning course they had taught. Some respondents were answering these questions based on a pre-pandemic course offering, while others were answering based on the spring 2020 semester. After gathering information about the course itself, we asked, "Did you make changes to $\{$ the course $\}$ because of the COVID-19 pandemic?" 34 respondents selected "yes" and were branched to a set of additional questions specific to the emergency remote teaching typically required by COVID-19. Their responses are presented here. In addition to these 34 respondents, two others briefly mentioned COVID as impacting their course in an openended question about what influenced the degree to which students were able to complete the service work in the course, even though they had selected "no" when asked if they made changes due to the pandemic. Specifically, respondent 39 wrote: "COVID-19 prevented in-depth software reviews and group work" and respondent 40 wrote "COVID."

\subsection{Survey Construction and Design}

The survey was designed based on an extensive review of the service learning literature, both general to undergraduate education and specific to computer and information science. The survey was subjected to three rounds of revisions. First, we asked an advisory board of experts in service learning to comment on the content and flow of the survey. Second, we asked three computer science colleagues who had taught service learning courses on our campus to take the survey and provide feedback on the revised survey. Finally, after another set of revisions, we asked colleagues and acquaintances on three other college campuses to take the survey and provide feedback. The final survey can be found at http://bit.ly/ServiceLearning-CIS.

The survey was designed with close adherence to best practices in survey design [16]. The first task on the survey was a request that respondents read a definition of service learning so that we could eliminate those whose teaching was not consistent with the definition: "Service learning is an authentic education experience in which students provide service to a community partner while learning content knowledge, professional skills, and critical thinking. Service learning in computer and information science courses can 
take many forms, such as developing mobile apps; mentoring elementary or secondary students in programming projects; designing websites; and many other possibilities." To improve respondents' recollections of their service learning experiences, we began the survey by asking them to name the most recent service learning course they had taught. We piped that course name into questions throughout the survey so that they answered questions only about that course. To strengthen that experience in respondents' working memory, we asked several questions that forced recall of the specific instance (e.g., level of course, enrollment before and after, whether required or elective, nature of service done by students, etc.). Depending on the information sought, survey items took different forms (select all that apply, forced response of one choice, open ended). Also, since the survey was exploratory, many questions included a comment box where respondents could explain their answer.

\subsection{Sample Development}

We downloaded data from the U.S. Department of Education's Integrated Postsecondary Education Database System (IPEDS) [63] to create a list of U.S. institutions that awarded at least one associate's or bachelor's degree in computer and information science in 2015. Research assistants then visited websites of each of these schools to create a list of faculty email addresses stratified by type of institution (2-year, Historically Black Colleges and Universities, Hispanic-serving, liberal arts, research, and tribal college). We then sent invitations to take the survey in two ways: 1) through the SurveyMonkey interface; and 2) from a university email account with a link to the SurveyMonkey survey. We offered an incentive: the chance to enter a random drawing for one $\$ 100$ gift card or one of eight $\$ 50$ gift cards (respondents entered their name in a form, the data for which was stored separately from the main survey). Reminder emails were sent twice to non-respondents. Because the survey was completely anonymous, we have no way of reporting on the institutional characteristics of respondents.

\subsection{Data Analysis}

The resulting data took the form of numbers (from forced-response questions and select-all-that-apply) and open-ended comments. We generated descriptive statistics with the forced-response questions, including frequencies, range, and measures of central tendency (usually mean, but median when there were outliers). We conducted tests of difference across categories where possible (e.g., gender, project types, type of change), but found no statistically significant differences at $\mathrm{p}<.05$. Therefore, we report descriptive statistics for the entire sample. Because the study was exploratory, we included many options for participants to write in explanations and responses. We undertook inductive qualitative analysis of the open-ended responses in three phases, allowing themes to emerge from the data (i.e., we did not apply themes from theory or other a priori frameworks). Each phase included individual work and research team discussion and consensus. First, we read all responses to open-ended questions and "other, please explain" options written by the 88 respondents who had taught at least one service learning course. Although our focus was on those 34 respondents who had selected "yes" to have been affected by the pandemic, we wanted to include anyone who mentioned "pandemic" or "COVID" in case it helped us understand the research questions; we found two respondents who answered "no" to having made pandemic-related changes, but who mentioned COVID, as mentioned above. This set of cases became the corpus for the thematic analysis. Next, we reread all open-ended responses in these cases and classified themes by question. Each theme was defined in a memo, then discussed in multiple research meetings with all authors. We noted that some of the categories were the same across questions and agreed on a final set of categories that synthesized the question-level categories and foregrounded key aspects of the memos. The codes were then added to the data set by one author, who checked for consistency by reviewing his selections. Finally, we identified key relationships between open-ended and closed-response data to ensure we understood the context expressed by qualitative data in each case. For example, particularly important was understanding the nature of service provided and the degree to which students were able to complete it. The thematic categories serve as the outline of our results section.

\subsection{Sample Profile}

Faculty and Course Profiles. The sample consists of 34 responses based on those who indicated that the pandemic affected their teaching. Not all respondents answered every question, particularly when not relevant (e.g., service projects involved contributing to an open source community instead of a community partner). Faculty ranged in years of teaching experience from two to 37 years, with a mean of 15 years, as shown in Table 1 . Most respondents (65\%) taught five or more courses per year and while most $(91 \%)$ had teaching assistants, just over half (52\%) personally taught every section of their courses. About 71 percent of respondents identified as men, 23 percent as women, and 6 percent preferred not to disclose (see Table 2). Nearly a quarter (23\%) identified as a member of a historically marginalized group in computing. The most common undergraduate major reported was computer science $(n=23$, or $74 \%$ ), but 58 percent offered more than one major (see Table 3 ). Course levels included introductory or lower division (24\%), upper division or graduate level (64\%), or a combination of upper and lower division undergraduate (12\%) or upper division undergraduates and graduate students $(\mathrm{n}=1)$. Course enrollments ranged from 2 to 150 , with a median of 21 students. Three-quarters of faculty $(n=25)$ reported that the courses were required for majors, with the remaining elective; 7 of 33 respondents reported that the course was required for minors (see Table 3 ).

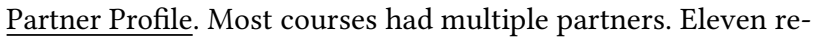
spondents (35\%) worked with partners who were based on their campus. Twenty-five respondents $(81 \%)$ reported that their partners were located off campus, but local to the institution. Twelve respondents $(39 \%)$ worked with non-local partners, either in the state/province $(n=8)$, the nation $(n=6)$, or international $(n=4)$. Nineteen respondents $(59 \%)$ identified partners with whom they had existing relationships, 13 (41\%) pursued new relationships, and 11 (34\%) were approached by a community partner rather than vice versa. Most partners $(n=28)$ were nonprofit organizations, including schools, government, churches, and hospitals; while about a quarter (14) were for-profit businesses (e.g., local farms and startups). 
Table 1: Teaching Experience/Load

\begin{tabular}{lc}
\hline \multicolumn{2}{c}{ Years Teaching in Higher Education } \\
\hline \hline Min & 2 \\
Max & 37 \\
Average & 14.7 \\
Standard Deviation & 8.3 \\
\hline \hline \multicolumn{2}{c}{ Teaching Load Per Year } \\
\hline \hline Min & 3 \\
Max & 7 \\
Average Number of Sections Personally Instructed & \\
Standard Deviation & 6 \\
\hline \hline & 2 \\
\hline \hline Min & 7 \\
Max & 5 \\
Average & 2 \\
Standard Deviation & 1 \\
\hline \hline & Number of Teaching Assistants Managed \\
\hline \hline Min & 7 \\
Max & 2 \\
Standard Deviation & 2 \\
\hline
\end{tabular}

Table 2: Demographic Information of Respondents

\begin{tabular}{lc}
\hline \multicolumn{2}{c}{ Gender Identification } \\
\hline \hline Man & 22 \\
Woman & 7 \\
Prefer Not to Disclose & 2 \\
\hline \hline \multicolumn{2}{c}{ Marginalized Racial/Ethnic Group Membership } \\
\hline \hline Yes & 7 \\
No & 21 \\
Prefer Not to Disclose & 2 \\
Other & 3 \\
\hline
\end{tabular}

\section{SURVEY RESULTS}

Thirty-four survey respondents reported that the COVID-19 pandemic caused them to make changes to the service learning courses that they were teaching. Not all of the faculty who reported making changes as a result of the pandemic had to make the emergency transition to online courses. Two courses were completely online and eight were hybrid (but not because of COVID-19) from the beginning. Those that began as in person and hybrid were completely online by end of March. We report below how faculty adjusted course requirements when they went online; student and partner outcome goals and what got prioritized; the reduction in important collaboration opportunities; factors related to student's abilities to stay committed to and engaged with projects in order to complete them successfully; and how student-partner relationships factored into project success.
Table 3: Course Characteristics

\begin{tabular}{|c|c|c|c|}
\hline \multicolumn{4}{|c|}{ Field/Major (select all that apply) } \\
\hline Computer Science & \multicolumn{3}{|c|}{23} \\
\hline Information Science & \multicolumn{3}{|c|}{10} \\
\hline Computer Engineering & \multicolumn{3}{|c|}{2} \\
\hline Software Engineering & \multicolumn{3}{|c|}{4} \\
\hline Data Science & \multicolumn{3}{|c|}{3} \\
\hline Web Development & \multicolumn{3}{|c|}{6} \\
\hline Other & \multicolumn{3}{|c|}{3} \\
\hline \multicolumn{4}{|c|}{ Level of Specific Course Taught (select all that apply) } \\
\hline Undergrad Introductory & \multicolumn{3}{|c|}{6} \\
\hline Undergrad Lower Div. & \multicolumn{3}{|c|}{6} \\
\hline \multicolumn{4}{|l|}{ Non-Introductory } \\
\hline Undergrad Capstone & \multicolumn{3}{|c|}{14} \\
\hline Undergrad Upper Div. Not & \multicolumn{3}{|c|}{10} \\
\hline \multicolumn{4}{|l|}{ Capstone } \\
\hline Graduate & \multicolumn{3}{|c|}{2} \\
\hline Combination & \multicolumn{3}{|c|}{4} \\
\hline \multicolumn{4}{|c|}{ Required or Elective Course } \\
\hline & Majors & & Minors \\
\hline Required & 25 & & 7 \\
\hline Elective, meets core requirement & 3 & & 5 \\
\hline $\begin{array}{l}\text { Elective, does not meet core } \\
\text { requirement }\end{array}$ & 5 & & 8 \\
\hline
\end{tabular}

Table 4: Location, Identification, and Type of Community Partners

\begin{tabular}{lc}
\hline \multicolumn{2}{c}{ Location of Partners (select all that apply) } \\
\hline \hline On campus & 11 \\
Local, off campus & 25 \\
State/Province & 8 \\
National & 6 \\
Abroad & 4 \\
\hline \hline \multicolumn{1}{c}{ How Partners were Identified (select all that apply) } \\
\hline \hline Existing relationship & 19 \\
Reached out to new partners & 13 \\
Approached by partner & 11 \\
\hline \hline \multicolumn{2}{c}{ Type of Community Partners Served (select all that apply) } \\
\hline \hline K-12 & 9 \\
Nonprofit & 14 \\
Government & 7 \\
Business & 14 \\
Healthcare & 4 \\
Community Center/Church & 2 \\
On-Campus Program & 2 \\
\hline
\end{tabular}


Table 5: COVID-Induced Service Learning Course Changes and Project Completion

\begin{tabular}{lc}
\hline \multicolumn{3}{c}{ Why Were Changes Made? (select all that apply) } \\
\hline \hline Campus closed and courses went fully online & 31 \\
Respondent/students could not come to campus (for & 4 \\
various reasons) & 2 \\
Community partner no longer able to participate & 15 \\
\hline \hline \multicolumn{2}{c}{ What Changes were Made? (select all that apply) } \\
\hline \hline Removed some of the requirements of the assignment & 3 \\
Removed the service assignment completely & 2 \\
Made the service assignment optional & 8 \\
Changed the final product provided to the community & \\
partner & 6 \\
\hline \hline & \\
\hline \hline
\end{tabular}

\subsection{Course Changes in Response to the Pandemic}

When asked to select all reasons why they made changes, all but three respondents (94\%) indicated that their campus had been closed. Four respondents reported that they made changes to their course because they could not go to campus for other reasons, while three reported that they changed the course because their community partner was no longer able to participate.

Of the 34 respondents who reported making at least one change from their original design, nearly half indicated in a "select all that apply" question that they removed some of the assignment's requirements $(n=15)$, while a much smaller number removed the service assignment completely $(n=3)$ or made it optional $(n=2)$. In open-ended responses, faculty members explained ways that they changed the requirements of the assignment based on local quarantine or social distancing guidelines. For example, Respondent 13 "required all meetings with partners to be remote," Respondent 28 required online presentation of the product, and Respondent 15 changed all aspects of the project to "online-only." Other faculty changed the modality of deliverables, asking for recorded video presentations (Respondent 16) or written reports (Respondent 18) instead of live, in-person final presentations. Two faculty members reported reducing the scope of the project to accommodate the more challenging work and collaboration context of the pandemic. For example, Respondent 3 wrote, "The community center was extremely helpful. Unfortunately, due to Covid and the transition to online, the partner, the students, and I had a hard time managing all the original expectations. Hence, I had to modify it accordingly." Despite these changes, however, a large majority of respondents reported that their students were able to successfully complete the service work (82\%). Only 6 stated that students' projects were not completed (18\%) (see Table 5).
Table 6: Nature of Service Projects (select all that apply)

\begin{tabular}{lc}
\hline Project Type (select all that apply) & Frequency \\
\hline Website development & 17 \\
Participate in open-source software & 5 \\
development & \\
Software/app prototype, but not implemented & 10 \\
Software/app implementation & 14 \\
Other software development & 6 \\
Data analysis & 10 \\
User testing & 11 \\
UX design & 9 \\
Hardware design & 2 \\
Teaching & 7 \\
Mentoring & 8 \\
Research and/or recommendation & 6 \\
IT/tech support & 6 \\
\hline
\end{tabular}

\subsection{Achieving Course Goals for Students and Partners}

Course goals were accomplished through involvement in several types of service projects (Table 6). We provided a "select all that apply" list of typical project types for respondents to choose from. In half of the courses, students created websites, while in a smaller percentage of courses students did other kinds of service, including participation in open-source software development projects $(5 / 34)$, prototyping but not implementing software (11/34), implementing software (14/34), data analysis (10/34), teaching (7/34), mentoring $(8 / 34)$, or user testing $(11 / 34)$. Eight faculty members constrained all students in a course to only one project type, while others allowed for significant variation.

To complement our understanding of the distribution of project types, we asked faculty to articulate student learning objectives in their own words and without influencing them through the question itself with an open-ended question, "Please briefly describe your goals for your students in $\{\{$ the course $\}\}$. Feel free to copy and paste the learning outcome goals from your syllabus or other document." Most respondents presented several types of goals and four general themes emerged from the analysis: technical skills, practical project and team management, interaction with partners, and professional and civic identity. The most commonly mentioned goals for students dealt with the development, synthesis, and/or application of some technical skill or combination of these, usually discussed in the context of a real-world experience. For example, Respondent 25 wrote, "Students should be able to analyze a problem and design an appropriate information system solution." The second most common theme was project management, which tended to be described not just in terms of planning and developing a product, but also in terms of interacting well with team members and community partners. For example, Respondent 7 listed fourteen competencies that combined product development tasks with teams and partners, ranging from "Conduct a project kickoff meeting with all project stakeholders" to "manage team conflict" to "present the final product." Several respondents specifically focused on studentpartner interactions, such as "build habits of professionalism via 
authentic external interactions and authentic, valuable required deliverables" (Respondent 14). Finally, some respondents appear to have been employing service learning specifically to humanize the field, building a sense of professional or civic identity with the field or sparking passion for computer and information science work and careers. Among other humanistic goals, Respondent 21 sought to "cultivate civic dispositions and skills that prepare [students] for a life of civic engagement."

In a similar open-ended question, we asked faculty to explain their goals for their community partners. However, in several cases, the explanation instead described roles for partners (e.g., give feedback to students). Three themes related to goals emerged from our analysis of their responses: a working product, reciprocity, and education. Creating a working product or service was the most commonly stated goal, like this detailed statement by Respondent 7:

To provide working software that delivers business value to the organization. Examples of value may include: reducing/replacing a manual/paper process for more efficient operation, developing an online presence for an organization to help with advocacy and/or lead capture, to develop a prototype of a concept and evaluate it before the organization further invests in the idea, to develop a data driven website to collect and report information for the organization (Respondent 7).

In terms of reciprocity, many responses were about relationship building or could be seen as goals for students or the department, such as "Build a positive relationship between the department and businesses within the community for: Internship opportunities, Job shadowing, Volunteer work, Collaborations, Community outreach, [and] Advisory Board" (Respondent 31). Finally, in some cases, skills or practice acquisition was the stated goal, as this brief comment by Respondent 5, "Improve their ability to do their job through the use of technology and a back-end database."

Respondents were then asked to compare the relative importance of student and community partner goals on a slider, then to explain their slider placement in a follow-up open-ended question. Several respondents (7/34) argued that student education or experience took priority over their partners' goals. For example, Respondent 20 wrote, "Our students are a higher priority; we work with our partners to enrich our student learning." Therefore, if they had to remove requirements, make changes to the assignment, or even remove the service learning component entirely, it is possible that faculty made this decision by prioritizing the learning experience for students rather than the deliverable for the partner. Two respondents wrote that they strove to both make community partners "happy" while providing for a good learning experience for students, even if this meant "re-defining" happy (Respondent 14, Respondent 17). Though course changes were done with students in mind, respondents did see inherent value in community partners, which potentially motivated them to attempt to maintain a service learning relationship even in pandemic conditions. For example, Respondent 8 states "My job is to teach students. We use community partners to accomplish this, with the side benefit of helping them." Respondent 8 removed the in-class participation component for the service learning activity but did not make other modifications.
While their stated priority was the students, the respondent saw partners as integral to the learning process. Indeed, if the partners are one of the main mechanisms for student learning, giving up on the project entirely makes no sense, even if collaboration is more difficult.

\subsection{Managing Disruption: Positive and Negative Outcomes}

5.3.1 Project Completion, Relationship Strength, and Ongoing Connection. We define positive service learning outcomes through the responses to open-ended questions: successful projects are those that are completed, meet the desired goals for partners, and furnish students with the desired learning goals. We asked faculty if their students were able to complete their service projects. About two-thirds (24) of faculty reported that students completed their service assignments during the academic term in which they were initiated. Some faculty allowed students to begin projects which a later set of students would complete. Four faculty members stated that although work had begun during an earlier term, students completed it in spring 2020. Similarly, Respondent 8 reported on a year-long service learning course sequence in which the longevity of the project helped, writing "It helped a lot that we started the capstone in Fall 2019. Progress did slow a bit after COVID-19 hit, but we still finished well." To some degree, these respondents attributed their successes to longer-term relationships with the community partners and projects that were already well underway before emergency remote instruction took effect. For example, Respondent 29 reported that "We had started the project from the start of the semester, students had completed half of the milestones before the interruption, they had established good relationships with their team members."

As suggested by open-ended responses about projects that were not completed, a lack of communication often resulted in crumbled relationships and incomplete projects. It is very likely then that lack of ongoing connection negatively influenced project completion. In most of the projects described as not completed, service work was initiated, but fell apart throughout the semester. Five respondents reported that the service work got started, but students did not complete it. For example, students in an upper division undergraduate machine learning course were designing and implementing software for a nonprofit, a city government, and a local farm; they lost communication with their partners and were forced to discontinue the in-progress projects (Respondent 3). Only one respondent reported that the project never got started. Completion is not the only criterion by which to judge "success," however.

5.3.2 Effects on Professional Interaction and Team Collaboration. As mentioned above, three community partners were unable to continue their participation when public health orders significantly disrupted the work of the organizations. While partner loss means that partners cannot evaluate or give feedback on the project, if the project is still completed with the expected goals, doing the project may result in learning outcomes. For example, while Respondent 6 noted that the service learning component of their course was not completed successfully, their students were still able to design prototypes without the help of the partners. But no 
partner means no professional interaction. Interaction with community partners is one of the key means by which students develop professionally in service learning courses. The sudden switch to remote learning also diminished students' important interaction with community partners, including the ability to experience partner sites in person. Respondents reported that the involvement of community partners was greatly reduced as a result of COVID-19, despite faculty members' best efforts to support students' goals to complete service assignments. Faculty described differing degrees of challenges maintaining communication and collaboration with community partners, from limits to the "capacity of the partner as they responded to covid-19" (Respondent 34) to a more severe degree of "disconnection with the partners after the transition due to COVID19" (Respondent 3) to a complete "loss of contact with community partner" (Respondent No. 6). Presumably, lack of interaction and feedback from the partner negatively affected students' acquisition of professional skills.

While anyone who taught or took classes that were originally intended to be in person during the pandemic likely had some negative experiences, it is nevertheless important to describe the continuity that communication technologies afforded the educational community. Losses of interaction were mitigated through online platforms and recording technologies. Two-thirds of respondents mentioned using some form of online meeting or video conferencing software (these mainly included Zoom, WebEx, and Microsoft Teams). Online conferencing technologies enabled synchronous and asynchronous interaction, including recorded student presentations. Access to these technologies was certainly an extremely important factor in ensuring that communication with partners was not completely lost and that projects were seen through to their end. One respondent mentioned that they had students record their presentations and then send them to partners, instead of presenting in person or live, over video conferencing (Respondent 16). Another respondent whose students were doing statistical analysis reports for a health center asked for such reports to be written and sent to the partner, in place of presentations (Respondent 18).

5.3.3 Nature of Service Provided May Affect Outcomes. For the most part, faculty made similar pandemic-related changes across project type, with the exception of mentoring and teaching. While we cannot compare completion and outcomes differences across project types due to the small sample size, faculty might have been more likely to remove the service completely when students were mentoring or teaching others. Of the three respondents who removed the service learning assignment completely, two projects involved both teaching and mentoring. Both projects involved partnerships with local middle and high schools, which had also switched to emergency remote instruction in many localities. Anticipating subsequent semesters of pandemic-affected teaching, one respondent echoed that the nature of the service project mattered and imagined changing the type of service entirely to more easily accommodate COVID restrictions: "I'm looking at engaging more with the $\mathrm{Hu}$ manitarian Free and Open Source Software (HFOSS) community, and having students spend more time working on humanitarian open-source projects, as opposed to onsite working face-to-face with clients." In contrast, one respondent regretted losing important opportunities for peer mentoring among students in the course, writing, "[Projects] had to be completed online, instead of in our class labs.... this did not allow more proficient [project] students to 'peer mentor' other [project] students.... very important component in Cyber Security” (Respondent 12).

5.3.4 Integrating Project Management and Meaning into Projects. Some respondents described course components that were likely instrumental in scaffolding students through the wide-ranging disruptions induced by the pandemic. To help students manage their timeline and stay accountable, Respondent 7's students were required to maintain and manage a project log and adhere to a strict deadline of providing community partners with something of value every two weeks. This structure might also have worked to build professional habits, making it easier to maintain a commitment to the project after the pandemic. Respondent 13 used a different approach, bolstering student motivation by attempting to get students to see themselves as moral agents in upholding software engineering codes of ethics. This could have influenced students to consider the broader, human implications of their work, and in doing so, engendered a drive to accomplish these projects to do good, despite the challenges and constraints of COVID's disruptions to education.

Although it is not possible to establish correlation by mixing qualitative and quantitative data in a small study, it could be suggested that students who were more personally committed to their work were more likely to complete projects successfully, despite the challenges of the pandemic. Respondent 14 emphasized building habits of professionalism via the authentic interactions of the service learning relationship; Respondent 20 stated that service learning is crucial for building students' confidence in their professions; and Respondent 28 mentioned that projects with local businesses both provided real-life experiences for students and hinted at post-graduation job opportunities. Mentions of habit development, as well as confidence building within a professional context allows students to begin to identify as CIS professionals themselves, which reinforces importance of engagement with the project and team.

\section{CONCLUSIONS AND IMPLICATIONS FOR COURSE DESIGN}

The majority of scholarship on service learning in postsecondary computer and information science are experience reports and there is much to be learned from them. Little research, however, aggregates faculty's experiences with service learning and to our knowledge, none addresses how faculty handle service learning when campuses and communities are required to shift to emergency remote work and instruction. Although this study was administered during an incredibly difficult time, the work is relevant to supporting what may be a growing number of online courses delivered under so-called normal circumstances in ramping up and supporting service learning experiences. While the sample is small, self-reported, and presents only faculty experiences, this paper contributes to scholarship on how to enable computer and information science faculty to support both students and community partners with effective service learning experiences, as well as some tentative provisions for how such experiences might be retained in the event of the next major interruption of higher education teaching and learning. We conclude by summarizing how our findings address 
the three research questions, then present implications for course design drawn from the data.

\subsection{Summary: How the COVID-19 Pandemic Affected CIS Service Learning Courses}

What changes did the COVID-19 pandemic lead to in service learning courses in computer and information science? Among our survey respondents, only three lost their community partners, despite the challenges to the non-profit sector. Although some respondents' results were consistent with the "non-delivery problem" of incomplete projects [50], most were able to adjust course requirementsoften reducing the scope of the project, eliminating some project requirements, and/or changing the modality of deliverables-in ways that allowed their students to complete their projects.

How did these changes affect course outcomes? Course adjustments were made with students in mind; respondents' commitment to educate swayed them to prioritize their students' learning experiences to achieve beneficial outcomes for partners. This is not to say that students received all the benefits expected from service learning projects. In particular, the student-student and student-partner interactions that provide students with professional development were slighted by the shift online, negatively affecting the ability to achieve course goals related to interaction with partners, student and departmental relationships with partners, and professional and civic identity.

How did faculty, students, and partners overcome the constraints imposed by the COVID-19 pandemic? Despite the extraordinary disruption, students and faculty made use of online communication technologies to mitigate some of the constraints imposed by the pandemic. Instructors and departments with long-term relationships with community partners seem to have fared better than those with newly-formed relationships. Also, projects that required intensive interpersonal interaction, such as mentoring or teaching, may have created insurmountable constraints. Yet for most project types, instructors who reported successful completion and outcomes for students reported using effective means to facilitate and/or maintain accountability to, engagement with, and commitment to their partners in order to bring about successful projects. We commend them for these achievements.

\subsection{Implications: Design for Disruption}

The effort that goes into designing a service learning course is critical for delivering positive outcomes for both students and community partners. Designing for disruption can be informed by the experiences shared by the respondents of this survey. Respondents who reported successful outcomes made course changes that allowed them to reach their course goals, achieving positive outcomes and avoiding negative outcomes. Below is a list of possible teaching recommendations:

- Plan for disruption and make sure students know what is in the plan.

- Imagine alternatives to accomplishing learning outcome goals for students. For example, draft a plan for what students will do for project feedback when there is no partner. Perhaps colleagues from other departments or graduate students can provide feedback. Make sure these colleagues know they might be asked to serve.

- Imagine which aspects of a project assignment are least important for achieving outcome goals and modularize components so that cutting back on requirements is easier. Some respondents completely ditched the service requirement, but many reduced its scope, which allowed students to engage with and serve their communities through civic engagement.

- Imagine which technologies you will use for students to collaborate with each other and their community partners in case of interruption. Make sure that students know how to use it for different goals (discussion, recording, user testing, etc.), just as you plan with students for the unlikely event of an active harmer or earthquake, as unpleasant as these conversations are. Check with partners to see which technologies they have access to and know how to use.

- Plan for routine communication with partners, early and often.

- Establish and maintain relationships with partners, even in the absence of a course to serve them. Make sure students know what to say and do to maintain effective relationships with partners.

- Require that students engage in ongoing, routine connection and communication with partners, even if they do not have the same technical infrastructure as campus. Some partners without technical infrastructure may still have telephone technologies. Low-tech communication is better for student and partner outcomes than no communication.

- Choose a project type that is more likely to continue in the face of disruptions.

- Mentoring and teaching projects are attractive to students, yet the data from this survey might suggest that connecting with other organizations that are likely to undergo disruption at the same time, but under different policies (e.g., middle and high schools; senior centers) are likely to be lost as partners, though this assertion needs to be further studied with a more generalizable sample.

- Have a backup project that allows students to make a positive civic contribution, such as involvement in Humanitarian Free and Open Source Software projects.

- Integrate structured project management into student assignments for ongoing accountability. This practice may be especially important in stressful situations, such as pandemics or other significant disruptions, when executive functioning can decrease [8].

- Get started with milestone completion early in the term.

- Create a rhythm of regular (i.e., weekly) deliverables that are part of students' grades. Predictable assignment structures are likely to be less taxing to students' executive functioning and will create touchpoints to make sure that students do not drop the ball or fall behind.

- Encourage student motivation and commitment through incorporation of personal meaning in projects. Faculty also described student commitment as a contributor of completion.

- Partners can be potential future employers. 
- Projects can support accomplishment of social good, a message that should be repeated to students throughout the project.

- Regularly describe students as professionals that uphold moral values in class discussion. Integrating a professionalized obligation to provide a valuable service for a client or for the community might facilitate prioritization of, and dedication to, the service learning assignment, having an overall positive effect on student commitment.

\section{ACKNOWLEDGMENTS}

Thank you to the survey respondents who participated in this study, and to our colleagues who helped in this research. Thank you to the National Science Foundation for the funding to conduct the study (\#1920851).

\section{REFERENCES}

[1] ABET Computing Accreditation Commission 2016. 2017-2018 Criteria for Accrediting Computing Programs, 2017-2018 | ABET. ABET.

[2] Astin, A.W. 1984. Student involvement: A developmental theory for higher education. Journal of College Student Personnel. 25, 4 (1984), 297-308.

[3] Backer, P. and Wei, B. 2010. Work in progress-recruiting Hispanic students into computing through community service learning. 2010 IEEE Frontiers in Education Conference (FIE) (Oct. 2010), F4D-1-F4D-2.

[4] Banerjee, S. and Mazur, N. 2018. Service Learning in Computing: Creating Computer Science Pipeline by Attracting and Engaging High School Students. J. Comput. Sci. Coll. 33, 6 (Jun. 2018), 173-175.

[5] Barker, L. et al. 2014. Results of a large-scale, multi-institutional study of undergraduate retention in computing. 2014 IEEE Frontiers in Education Conference (FIE) (Oct. 2014), 1-8.

[6] Biden Signs Federal Stimulus - Billions For NPO Services, Public Service: https://www.thenonprofittimes.com/news/federal-stimulus-includes-billionsfor-npo-services-payments/. Accessed: 2021-03-26.

[7] Bizot, B. et al. 2020. Results of a summer 2020 survey of computer science faculty: The transition to online teaching last spring and planning for the fall. Computing Research Association.

[8] Boals, A. and Banks, J.B. 2020. Stress and cognitive functioning during a pandemic: Thoughts from stress researchers. Psychological Trauma: Theory, Research, Practice and Policy. 12, S1 (Aug. 2020), S255-S257. DOI:https://doi.org/10. 1037/tra0000716.

[9] Bopp, C. et al. 2017. Disempowered by Data: Nonprofits, Social Enterprises, and the Consequences of Data-Driven Work. Proceedings of the 2017 CHI Conference on Human Factors in Computing Systems (New York, NY, USA, 2017), 3608-3619.

[10] Celio, C.I. et al. 2011. A Meta-Analysis of the Impact of Service-Learning on Students. Journal of Experiential Education. 34, 2 (Sep. 2011), 164-181. DOI:https: //doi.org/10.1177/105382591103400205.

[11] Cicirello, V.A. 2013. Experiences with a Real Projects for Real Clients Course on Software Engineering at a Liberal Arts Institution. J. Comput. Sci. Coll. 28, 6 (Jun. 2013), 50-56.

[12] Connolly, R.W. 2012. Is There Service in Computing Service Learning? Proceedings of the 43rd ACM Technical Symposium on Computer Science Education (New York, NY, USA, 2012), 337-342.

[13] Costa, J.T. 2017. Service Learning, Project Management and Professional Development. Business Education Innovation Journal. 9, 2 (2017), 32-38.

[14] Daempfle, P.A. 2003. An analysis of the high attrition rates among first year college science, math, and engineering majors. Journal of College Student Retention: Research, Theory and Practice. 5, 1 (Jan. 2003), 37-52. DOI:https: //doi.org/10.2190/DWQT-TYA4-T20W-RCWH.

[15] Dark, M.J. 2004. Civic Responsibility and Information Security: An Information Security Management, Service Learning Course. Proceedings of the 1st Annual Conference on Information Security Curriculum Development (New York, NY, USA, 2004), 15-19.

[16] Dillman, D.A. et al. 2014. Internet, phone, mail, and mixed-mode surveys: the tailored design method. Wiley.

[17] Egan, M.A.L. and Johnson, M. 2010. Service Learning in Introductory Computer Science. Proceedings of the Fifteenth Annual Conference on Innovation and Technology in Computer Science Education (New York, NY, USA, 2010), 8-12.

[18] Eyler, J. et al. 2001. At A Glance: What We Know about The Effects of ServiceLearning on College Students, Faculty, Institutions and Communities, 1993- 2000: Third Edition. Higher Education. (Aug. 2001).

[19] Farahmandpour, H. and Shodjaee-Zrudlo, I. 2015. Redefining Service-Learning for the Purpose of Social Change Within Education. The SAGE Sourcebook of
Service-Learning and Civic Engagement. SAGE Publications, Inc. 47-52.

[20] Gabrysiak, G. et al. 2013. Cooperating with a non-governmental organization to teach gathering and implementation of requirements. 2013 26th International Conference on Software Engineering Education and Training (CSEE T) (May 2013), 11-20.

[21] Giannakos, M.N. et al. 2017. Understanding student retention in computer science education: The role of environment, gains, barriers and usefulness. Education and Information Technologies. 22, 5 (Sep. 2017), 2365-2382. DOI:https://doi.org/ 10.1007/s10639-016-9538-1.

[22] Grønbjerg, Kirsten A. et al. 2020. Indiana Nonprofits and COVID-19: Impact on Services, Finances, and Staffing. Technical Report \#IV. Indiana University O'Neill School of Public and Environmental Affairs.

[23] Guzdial, M. 2013. Exploring Hypotheses About Media Computation. Proceedings of the Ninth Annual International ACM Conference on International Computing Education Research (New York, NY, USA, 2013), 19-26.

[24] Habley, W.R. et al. 2012. Increasing Persistence: Research-Based Strategies for College Student Success. John Wiley \& Sons, Incorporated.

[25] Hsin, W.-J. and Ganzen, O. 2008. Computer Literacy in International Service Learning at Park University. J. Comput. Sci. Coll. 23, 4 (Apr. 2008), 163-167.

[26] Ihrke, Douglas et al. 2020. The COVID-19 Effect on the Wisconsin Nonprofit Sector. Technical Report \#Report One. The Helen Bader Institute for Nonprofit Management.

[27] Jessup, E.R. et al. 2005. Report from the trenches: Implementing curriculum to promote the participation of women in computer science. Journal of Women and Minorities in Science and Engineering. 11, 3 (2005), 273-294.

[28] Johnson, N. et al. 2020. U.S. Faculty and Administrators' Experiences and Approaches in the Early Weeks of the COVID-19 Pandemic. Online Learning. 24, 2 (Jun. 2020), 6-21.

[29] Joint Task Force on Computing Curricula et al. 2013. Computer Science Curricula 2013: Curriculum Guidelines for Undergraduate Degree Programs in Computer Science. ACM.

[30] Kiely, R. et al. 2018. Understanding service-learning basics and best practices. Global health experiential education: From theory to practice. A.N. Arya and J. Evert, eds. Routledge. 85-95.

[31] Kuh, G.D. et al. 2008. High-impact educational practices: what they are, who has access to them, and why they matter. Association of American Colleges and Universities.

[32] Kuh, G.D. et al. 2010. Student Success in College: Creating Conditions That Matter. John Wiley \& Sons.

[33] Lasserre, P. 2011. Service Learning: An HCI Experiment. Proceedings of the 16th Western Canadian Conference on Computing Education (New York, NY, USA, 2011), 12-16.

[34] Le Dantec, C.A. and Edwards, W.K. 2008. The View from the Trenches: Organization, Power, and Technology at Two Nonprofit Homeless Outreach Centers. Proceedings of the 2008 ACM Conference on Computer Supported Cooperative Work (New York, NY, USA, 2008), 589-598.

[35] LeBeau, B. et al. 2012. Student and high-school characteristics related to completing a science, technology, engineering or mathematics (STEM) major in college. Research in Science \& Technological Education. 30, 1 (2012), 17-28. DOI:https://doi.org/10.1080/02635143.2012.659178.

[36] Lincke, S.J. 2007. Network security auditing as a community-based learning project. ACM SIGCSE Bulletin. 39, 1 (Mar. 2007), 476-480. DOI:https://doi.org/10. $1145 / 1227504.1227472$.

[37] Liu, Y. and DeBello, J.E. 2018. Academic Service Learning in Undergraduate and Graduate Computer Science Courses to Foster Engagement and Real World Experience. J. Comput. Sci. Coll. 33, 3 (Jan. 2018), 135-140.

[38] Margolis, J. and Fisher, A. 2002. Unlocking the clubhouse: Women in computing. MIT Press.

[39] Merkel, C. et al. 2007. Managing Technology Use and Learning in Nonprofit Community Organizations: Methodological Challenges and Opportunities. Proceedings of the 2007 Symposium on Computer Human Interaction for the Management of Information Technology (New York, NY, USA, 2007).

[40] Mertz, J. 2015. Computing for the Social Good and Cultivating Cultures for Ethical Computing. SIGCAS Comput. Soc. 45, 2 (Jul. 2015), 39-40. DOI:https: //doi.org/10.1145/2809957.2809970.

[41] Mohmmed, A.O. et al. 2020. Emergency remote teaching during Coronavirus pandemic: the current trend and future directive at Middle East College Oman. Innovative Infrastructure Solutions. 5, 3 (Jul. 2020), 72. DOI:https://doi.org/10. 1007/s41062-020-00326-7.

[42] Newhouse, Chelsea L. Nonprofit Sector Lost Over 7\% of its Workforce In the First Year of the Pandemic. Johns Hopkins Center for Civil Society Studies.

[43] Osborne, R.B. et al. 2010. Teaching with Robots: A Service-learning Approach to Mentor Training. Proceedings of the 41st ACM Technical Symposium on Computer Science Education (New York, NY, USA, 2010), 172-176.

[44] Pascarella, E.T. and Terenzini, P.T. 1991. How college affects students: Findings and insights from twenty years of research. Jossey-Bass.

[45] Payton, J. et al. 2015. The effects of integrating service learning into computer science: an inter-institutional longitudinal study. Computer Science Education. 
25, 3 (Jul. 2015), 311-324. DOI:https://doi.org/10.1080/08993408.2015.1086536.

[46] Pollock, L. et al. 2018. A Computer Science Study Abroad with Service Learning Design and Reflections. Proceedings of the 49th ACM Technical Symposium on Computer Science Education (New York, NY, USA, 2018), 485-490.

[47] Porter, L. and Simon, B. 2013. Retaining Nearly One-third More Majors with a Trio of Instructional Best Practices in CS1. Proceeding of the 44th ACM Technical Symposium on Computer Science Education (New York, NY, USA, 2013), 165-170.

[48] Quesenberry, J. et al. 2012. Experiences in Service-learning Pedagogy: Lessons for Recruitment and Retention of Under Represented Groups. Proceedings of the 50th Annual Conference on Computers and People Research (New York, NY, USA, 2012), 89-90.

[49] Reiser, S.L. and Bruce, R.F. 2009. Fabrication: A Tangible Link Between Computer Science and Creativity. Proceedings of the 40th ACM Technical Symposium on Computer Science Education (New York, NY, USA, 2009), 382-386.

[50] Rosmaita, B.J. 2007. Making Service Learning Accessible to Computer Scientists. Proceedings of the 38th SIGCSE Technical Symposium on Computer Science Education (New York, NY, USA, 2007), 541-545.

[51] Salamon, Lester M. and Newhouse, Chelsea L. 2020. The 2020 Nonprofit Employment Report. Technical Report \#48. Johns Hopkins Center for Civil Society Studies.

[52] Sanderson, P. and Vollmar, K. 2000. A Primer for Applying Service Learning to Computer Science. Proceedings of the Thirty-first SIGCSE Technical Symposium on Computer Science Education (New York, NY, USA, 2000), 222-226.

[53] Shneiderman, B. et al. 2006. Making a Difference: Integrating Socially Relevant Projects into HCI Teaching. CHI '06 Extended Abstracts on Human Factors in Computing Systems (New York, NY, USA, 2006), 41-44.

[54] Slivovsky, L.A. et al. 2007. Enabling Creativity in Capstone Design. Proceedings of the 2007 Symposium on Science of Design (New York, NY, USA, 2007), 32-33.

[55] Speck, B.W. and Hoppe, S.L. eds. 2004. Service-learning: history, theory, and issues. Praeger.

[56] Stone, J.A. et al. 2012. Community-based Projects for Computing Majors: Opportunities, Challenges and Best Practices. Proceedings of the 43rd ACM Technical Symposium on Computer Science Education (New York, NY, USA, 2012), 85-86.
[57] Strayhorn, T.L. 2012. College students' sense of belonging: a key to educational success for all students. Routledge.

[58] Tan, J. and Phillips, J. 2005. Incorporating Service Learning into Computer Science Courses. J. Comput. Sci. Coll. 20, 4 (Apr. 2005), 57-62.

[59] The CARES Act Works for All Americans | U.S. Department of the Treasury: https://home.treasury.gov/policy-issues/cares. Accessed: 2020-08-28.

[60] The Healthy Minds Network 2020. The impact of COVID-19 on college student well-being. American College Health Association.

[61] Thoms, B. and Eryilmaz, E. 2018. Social Software Design To Facilitate Servicelearning In Interdisciplinary Computer Science Courses. Proceedings of the 49th ACM Technical Symposium on Computer Science Education (New York, NY, USA, 2018), 497-502.

[62] Tinto, V. 1975. Dropout from Higher Education: A Theoretical Synthesis of Recent Research. Review of Educational Research. 45, 1 (Jan. 1975), 89-125. DOI:https://doi.org/10.2307/1170024.

[63] U.S. Department of Education 2016. Integrated Postsecondary Education Data System. Institute of Education Sciences, National Center for Education Statistics.

[64] Voida, A. et al. 2011. Homebrew Databases: Complexities of Everyday Information Management in Nonprofit Organizations. Proceedings of the SIGCHI Conference on Human Factors in Computing Systems (New York, NY, USA, 2011), 915-924.

[65] Werner, M. and MacLean, L.M. 2006. Building Community Service Projects Effectively. J. Comput. Sci. Coll. 21, 6 (Jun. 2006), 76-87.

[66] Yorio, P.L. and Feifei Ye 2012. A Meta-Analysis on the Effects of Service-Learning on the Social, Personal, and Cognitive Outcomes of Learning. Academy of Management Learning \& Education. 11, 1 (Mar. 2012), 9-27.

[67] Young, Emily et al. 2020. Unprecedented Disruption: COVID-19 Impact on San Diego Nonprofits Nonprofits. Technical Report \#5. The Nonprofit Institute at University of San Diego.

[68] Zegura, E.W. 2014. Achieving and Assessing Service in Computing Service Learning: Lessons from Computing for Good - ProQuest. International Journal for Service Learning in Engineering. (2014), 424-438. DOI:https://doi.org.colorado. idm.oclc.org/10.24908/ijsle.v0i0.5561. 